\title{
Imagem de Fabiano
}

\author{
ALCIDES VILLAÇA
}

I

$\mathrm{E}$

M IDOS TEMPOS, nossa classe de adolescentes leu Vidas secas ${ }^{1}$ como cumprimento de tarefa escolar. Discutimos a obra em sala, e a impressão geral não foi muito favorável. O livro não nos oferecia uma “aventura”, propriamente; o "enredo" era meio solto e praticamente não havia diálogos. Mas o episódio da morte da Baleia (e uma ou outra passagem com alguma força anedótica) fizera-nos respeitar um escritor capaz de comover a gente.

Anos mais tarde, fui encontrar na crítica de Álvaro Lins (1970) restrições a essa obra-prima de Graciliano Ramos. Sem deixar de reconhecer e admirar a excelência da narrativa, apontava-lhe o crítico estes "dois defeitos consideráveis":

os capítulos dessa novela construída em quadros não se articulam formalmente com bastante firmeza e segurança. Cada um deles é uma peça autônoma, vivendo por si mesma, com um valor literário tão indiscutível, aliás, que se poderia escolher qualquer um, conforme o gosto pessoal, para as antologias [...]

$\mathrm{O}$ outro defeito é o excesso de introspecção em personagens tão primários e rústicos, estando constituída quase toda a novela de monólogos interiores [...]

Tais ressalvas, formuladas por um grande crítico na década de 1940, não dariam sustentação a nossas impressões de leitores adolescentes? Pareceu-me que, no elaborado plano das considerações técnicas e do princípio da verossimilhança, Álvaro Lins também se ressentira da estrutura meio descosida e do mutismo meditativo das personagens.

Minha tarefa de hoje - focalizar a personagem Fabiano ${ }^{2}$ - leva-me a revisitar as antigas impressões de leitor adolescente e o texto crítico de Álvaro Lins, sem descuidar do que colhi da fortuna crítica de Graciliano.

Parece-me agora mais fácil avaliar o quanto os supostos "defeitos consideráveis" são, na verdade, marcas e trunfos criativos dessa novela que se desenvolveu a partir de um conto: o autor, valendo-se pela primeira vez de um narrador ficcional em terceira pessoa, deseja perseguir um tipo de vivência a que falta exatamente o sentido de história como ordenação, como progressão dos acontecimentos, como sucessão épica reveladora ou qualificação do tempo em avanço, num universo de personagens carentes da articulação plena da linguagem verbal, do discurso pelo qual pudessem se dar a conhecer de modo mais exteriorizado e objetivo. No entanto, dentro de si mesmas, no silêncio de cada uma, há história acumulada, percepções intensas e reflexão contínua. A miséria física de sua situação tem na precariedade e na insuficiência das palavras um agravo essencial, modulado diferentemente em cada uma das criaturas. 
Os leitores das memórias de Graciliano recolhidas em Infância (1945) - se não o mais comovente, o mais comovido de seus livros - haverão de reconhecer o quanto há da formação pessoal do autor na projeção de experiências narradas em Vidas secas, experiências que incluem, entre outras, uma sede abrasadora, a dor das pancadas injustas, o suplício das botinas apertadas, o medo, a insegurança, e - não por último - a dificuldade com as palavras, faladas e escritas. Enquanto não se completou sua tardia alfabetização, o menino Graciliano torturava-se com os signos enigmáticos dos livros, com as histórias que não fluíam; plenamente alfabetizado, entregou-se perdidamente ao mundo da ficção, onde se instalou para viver outras vidas. Mais tarde, já escritor, revelaria com seu estilo uma responsabilidade tão extremada com a linguagem que essa só lhe saía em registros de auto-avaliação e desconfiança muito sofridos - paradigmas de uma ética rigorosíssima, interpretada por Otto Maria Carpeaux (1943) como evidência de um espírito radical para quem dizer o mundo implica tamanho senso de seleção e eliminação das palavras que o próprio mundo se arrisca a ser eliminado.

Tamanho rigor não é efeito de conviç̧ões ideológicas mediadoras: nasce de experiências brutas como a relatada em Infància, no capítulo "O moleque José": o menino Graciliano, numa tentativa de cair nas boas graças do pai tirânico, busca mostrar-se seu aliado, pretendendo ajudá-lo na aplicação do castigo físico que o homem está infligindo a um moleque. Mas o pai se irrita com a iniciativa do filho, abandona a vítima e - palavras textuais - "levantou-me pelas orelhas e concluiu a punição transferindo para mim todas as culpas do moleque. Fui obrigado a participar do sofrimento alheio" (Ramos, 1970 , grifo meu).

Os protagonistas da ficção de Graciliano costumam compor-se de sofrimentos, defeitos, limites e obsessões do autor. Em Vidas secas, Fabiano é personagem aparentemente distante da pessoa autoral; protagoniza objetivamente parte da saga de um vaqueiro e de sua família retirante. A condição mais primitiva (Álvaro Lins) da personagem impediu, de fato, o recurso da primeira pessoa, mas há algum compartilhamento de idéias e linguagem, tanto quanto há os fatais abismos entre os níveis de expressão do narrador e do protagonista. ${ }^{3}$

III

Para atender à compreensão mais particular da personagem Fabiano, não me esqueço de que ela é composta no conjunto de uma narrativa, num sistema de relações com todas as outras personagens, com o espaço em que vive, com o tempo que corre; não me esqueço de que ela nasce como efeito de narração, como criatura particularizada por uma forma de narrar, como um ser de palavras que ganha imagem e vida a cada vez que se pronuncia o discurso, com seus ritmos e seus apelos à imaginação. É impossível compreender Fabiano sem compreender sinhá Vitória, os meninos, a cachorra Baleia, o soldado amarelo, o patrão, seu Tomás da bolandeira; sem compreender o ofício de vaqueiro, a caatinga, a cultura popular nordestina, o ciclo das estações no sertão etc. etc. 


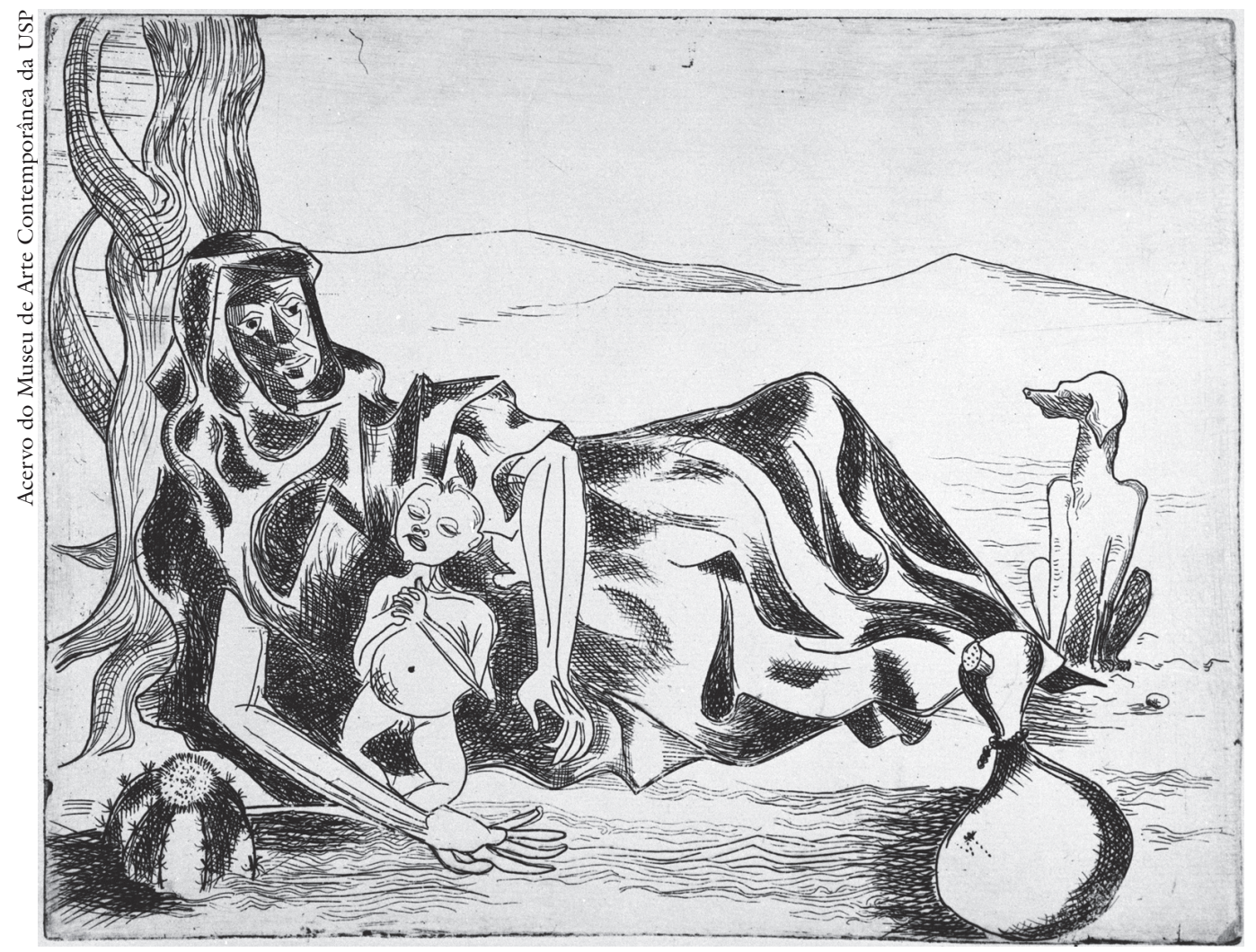

Seca do Nordeste, 1950. Água forte s/papel. Aldemir Martins.

Considerando-se esse intrincado conjunto de relações, a pergunta que me compete responder soa tremenda: - Quem é Fabiano?

Reconheçamos logo que essa questão é muito menos aflitiva para o leitor do que para o próprio vaqueiro. A questão da identidade, a questão do quem sou é obsessiva no universo das inquirições, da tartamudez e das hesitações profundas de Fabiano.

Uma hesitação essencial e permanente representa-se entre ser homem e ser bicho. Como todo bicho, Fabiano quer viver; como todo homem, Fabiano pensa e sonha. Lê-se logo no primeiro capítulo da novela ("Mudança”) esta passagem que fala do querer viver e do sonhar:

Aquilo era caça bem mesquinha, mas adiaria a morte do grupo. E Fabiano queria viver. Olhou o céu com resolução. A nuvem tinha crescido, agora cobria o morro inteiro. Fabiano pisou com segurança, esquecendo as rachaduras que lhe estragavam os dedos e os calcanhares.

Do plano rasteiro da caça bem mesquinha passa-se ao olbou para o céu com resolução: esse olhar pode sugerir algo de místico, mas logo reconhecemos seu objeto: a nuvem que tinha crescido e que podia ser chuva. A possibilidade real excita sonhos em progressão:

a catinga ressuscitaria, a semente de gado voltaria ao curral, ele, Fabiano, seria 
o vaqueiro daquela fazenda morta [...] Os meninos gordos, vermelhos, brincariam no chiqueiro das cabras, sinhá Vitória vestiria saias de ramagens vistosas. As vacas povoariam o curral. E a catinga ficaria toda verde.

As palavras com que Fabiano se define - bicho, homem - também oscilam: bicho expõe a condição de animal miserável, mas logo fala da disposição vitoriosa daquele que, dia por dia, consegue sobreviver:

- Você é um bicho, Fabiano.

Isto para ele era motivo. Sim senhor, um bicho, capaz de vencer dificuldades [...] Aparecera como um bicho, entocara-se como um bicho, mas criara raízes, estava plantado.

$[\ldots]$

Estava escondido no mato como tatu. Mas um dia sairia da toca, andaria com a cabeça levantada, seria um homem.

- Um homem, Fabiano.

Interessa-me perseguir, na intimidade de Fabiano, esse movimento pendular entre a sobrevivência e o sonho, entre o limite da ação e a projeção imaginária, entre a condição dada e a condição desejada. Deve-se notar como o narrador praticamente rejeita, em toda a novela, a utilização do presente do indicativo, não obstante a narração guarde o efeito de uma presentificação contínua: as ações e os pensamentos de Fabiano chegam-nos nas formas do pretérito ou do futuro do pretérito, atando as marcas de uma predestinação a um futuro vagamente divisado.

De um lado, as experiências todas do passado de Fabiano sugerem que ele está a repetir os mesmos passos imemoriais de outros tantos fabianos, condenado a refazer mecanicamente gestos ancestrais:

A cabeça inclinada, o espinhaço curvo, agitava os braços para a direita e para a esquerda. Esses movimentos eram inúteis, mas o vaqueiro, o pai do vaqueiro, o avô e outros antepassados mais antigos haviam-se acostumado a percorrer veredas, afastando o mato com as mãos. E os filhos já começavam a reproduzir o gesto hereditário.

O narrador é sugestivo: o mundo de Fabiano incorpora repetições esvaziadas de sentido, ações em que há esforço sem proveito, em que a memória existe não como lição a ser aproveitada em consciência, mas repetida sem questionamento pelo corpo acostumado. O passado de Fabiano oferece-se como tradição cristalizada, confundindo-se com um universo arcaico à margem das mudanças e da civilização. A história de Fabiano tende a naturalizar-se, a integrar-se aos ritos de uma existência predeterminada, sem nenhuma capacidade de reorientação. No mundo da natureza, no mundo dos gestos hereditários, a passagem do tempo se confunde com a propulsão dos instintos.

De outro lado, porém, não houvesse em Fabiano mais do que a repetição desses gestos, não houvesse nele nada além da inconsciência e da resignação, não seria a 
personagem dramática que é, nem a novela provocaria os leitores com a disposição que João Cabral de Melo Neto (1986) reconheceu na escritura de Graciliano:

Falo somente para quem falo:

quem padece sono de morto

e precisa um despertador

acre, como o sol sobre o olho;

que é quando o sol é estridente,

a contra-pelo, imperioso,

e bate nas pálpebras como

se bate numa porta a socos.

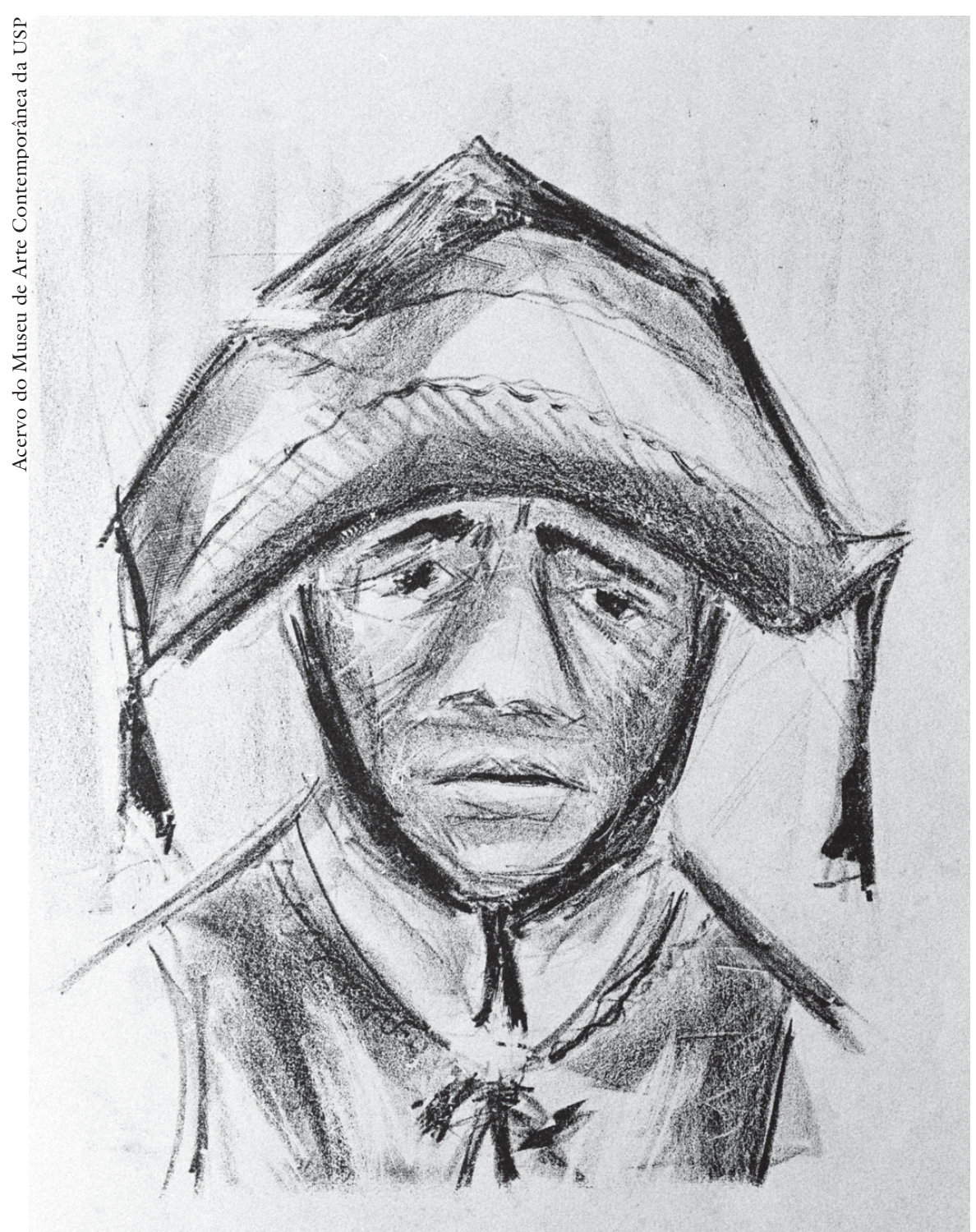

Vaqueiro, 1952. Litografia s/papel. Mário Cravo Jr. 
Existe, sim, para Fabiano, o tempo do futuro. Em sugestivas frases do capítulo "Fuga" - "Recordou-se dos animais feridos e logo afastou a lembrança. Que fazia ali virado para trás? Os animais estavam mortos" - há, ainda que em meio a hesitações, a disposição de seguir em frente. Discutindo com sinhá Vitória "se não seria bom tornarem a viver como tinham vivido, muito longe [...] numa casinha protegida pela bolandeira de seu Tomás [...] acabaram reconhecendo que não valeria a pena, porque estariam sempre assustados, pensando na seca". E o leitor encontrará, nas últimas frases da novela, um final ambíguo, em que a impressão de circularidade do destino daquela família, de novo obrigada ao movimento de fuga, não pode deixar de registrar a renovação de esperanças que o casal alimenta seguindo para o sul, metidos naquele sonho, acreditando numa nova terra. Não se fale, aqui, em otimismo de Graciliano; fale-se em movimento (e movimento também íntimo) das personagens. Volto, assim, à motivação inicial deste ensaio: caracterizar em Fabiano uma vitalidade que nem sempre se costuma reconhecer, e que se prende exatamente ao que seria um dos pontos mais frágeis da personagem: a capacidade de pensar, de aprender e de articular as palavras.

A resposta à pergunta Quem é Fabiano? não pode, evidentemente, restringir-se a uma tipificação simples da figura de um retirante, de um vaqueiro, de um homem embrutecido pelas experiências da fome e da sede, de um trabalhador explorado e humilhado. Sendo tudo isso, Fabiano é também um homem que pensa nisso o tempo todo, e o faz passando por extremas dificuldades com a busca e o emprego das palavras: palavras que deveriam nomear e aclarar suas questões, articular causas e efeitos, hipóteses e probabilidades, defendê-lo minimamente dos abusos - mas que não lhe ocorrem, ou, quando surgem, de nada lhe valem. É o que acontece durante quase toda a ação da novela.

Antes de analisar um momento que me parece muito especial no livro, em que talvez esteja o que há de mais esperançoso e afirmativo nessa história de danações, gostaria de avaliar mais singularmente as relações que Fabiano mantém com as palavras, as suas e as dos outros. Reconheça-se, desde logo, que um dos dramas do vaqueiro está em divisar vagamente a linguagem como uma ordem desejada e uma ameaça temível, como um patamar de razões que lhe parecem tão sólidas quanto fora de seu alcance, e mesmo como uma inutilidade, diante das fortes intempéries deste mundo.

De que palavras, enfim, cuida Fabiano?

a) Há as palavras da reza, o reconhecimento da oração forte, quando cura no rasto a bicheira da novilha, cumprindo e repetindo integralmente o rito herdado;

b) Há as poucas palavras do seu dia-a-dia, uma linguagem cantada, monossilábica e gutural, exclamações, onomatopéias; linguagem que pode usar, indistintamente, com os bichos e com as pessoas; 
c) Há as palavras interrogativas, as palavras que perguntam e ficam sem resposta, como as que pronunciou em menino para o seu pai e como as que seus meninos pronunciam para ele, confundindo-o:

“- Esses capetas têm idéias...”;

d) Hás as palavras compridas e difíceis da gente da cidade, palavras que em vão tenta reproduzir, e lhe parecem chaves perigosas de um mundo de logros e desnorteios: "Se aprendesse qualquer coisa, necessitaria aprender mais, e nunca ficaria satisfeito";

e) Há as palavras que precisa respeitar porque traduzem uma autoridade incontestável, ainda que injusta. Governo é governo. As palavras incompreensíveis do patrão, a ordem do soldado, o argumento do arrecadador de impostos obtêm dele como resposta ou a resignação imediata ou a patética tentativa de discurso, em que sobram os conectivos que nada conectam, como na réplica ao soldado amarelo:

“- Isto é. Vamos e não vamos, Quer dizer. Enfim, contanto, etc. É conforme".

Mas em Vidas secas há mais que o arrolamento das deficiências, equívocos ou silêncios de Fabiano diante do universo das palavras; há pensamento e movimento, há busca e, mesmo, uma intensa revelação do sentido da linguagem. E chego aqui a uma passagem a que dou um peso crucial, e que reservei para o acento da interpretação que busco fazer do protagonista e, por conta disso, também da novela mesma, e de um pouco do seu autor.

Trata-se de desta passagem, que está em "O mundo coberto de penas", título ambíguo e sugestivo do penúltimo capítulo do livro (e, num primeiro momento, também o título do romance):

O mulungu do bebedouro cobria-se de arribações. O casal agoniado sonhava desgraças. O sol chupava os poços, e aquelas excomungadas levavam o resto da água, queriam matar o gado.

Sinhá Vitória falou assim, mas Fabiano resmungou, franziu a testa, achando a frase extravagante. Aves matarem bois e cabras, que lembrança! Olhou a mulher, desconfiado, julgou que ela estivesse tresvariando. Foi sentar-se no banco do copiar, examinou o céu limpo, cheio de claridades de mau agouro, que a sombra das arribações cortava. Um bicho de penas matar o gado! Provavelmente sinhá Vitória não estava regulando.

Fabiano estirou o beiço e enrugou mais a testa suada: impossível compreender a intenção da mulher. Não atinava. Um bicho tão pequeno! Achou a coisa obscura e desistiu de aprofundá-la. Entrou em casa, trouxe o aió, preparou um cigarro, bateu com o fuzil na pedra, chupou uma tragada longa. Espiou os quatro cantos, ficou alguns minutos, voltado para o norte, coçando o queixo.

- Chi! Que fim de mundo! 
Não permaneceria ali muito tempo. No silêncio comprido só se ouvia um rumor de asas.

Como era que sinhá Vitória tinha dito? A frase dela tornou ao espírito de Fabiano e $\operatorname{logo}$ a significação apareceu. As arribações bebiam a água. Bem. O gado curtia sede e morria. Muito bem. As arribações matavam o gado. Estava certo. Matutando, a gente via que era assim, mas sinha Vitória largava tiradas embaraçosas. Agora Fabiano percebia o que ela queria dizer. Esqueceu a infelicidade próxima, riu-se encantado com a esperteza de sinhá Vitória. Uma pessoa como aquela valia ouro. Tinha idéias, sim senhor, tinha muita coisa no miolo. Nas situações difíceis encontrava saída. Então! Descobrir que as arribações matavam o gado! E matavam. Aquela hora o mulungu do bebedouro, sem folhas e sem flores, uma garrancharia pelada, enfeitava-se de penas.

Escritor de palavras medidas, sobretudo em Vidas secas, Graciliano precisa ser lido de modo amplificado, diria, para que não se percam as sugestões mais agudas de uma expressão concisa ou de um breve momento. O texto desse artista que parece querer eliminar o mundo, pela exigência dos paradigmas com que vai eliminando as palavras (Carpeaux), exibe nas palavras que ficam uma força por vezes insuspeitada, que só numa análise mais detida se revela à leitura, dando voz a uma comoção tão intensa quanto bem protegida.

Prenunciando tempos terríveis, "o mulungu do bebedouro cobria-se de arribações". Lembremos que mulungu é árvore sombreira, carregada de folhas, e as arribações são as avoantes, que na retirada vão consumindo o resto da água que encontram. Diante desse quadro, "o casal agoniado sonhava desgraças". Sem lhe dar a palavra, o narrador refere-se à observação feita em voz alta pela mulher: “aquelas excomungadas levavam o resto de água, queriam matar o gado".

Como logo em seguida lemos "Sinhá Vitória falou assim, mas Fabiano resmungou", precisamos traduzir por nossa conta as palavras que correspondem àquele falou assim, e que não podem fugir muito de algo como "essas excommngadas vão levar a água, querem matar o gado". Importa-me aqui atentar para as razões do resmungo de Fabiano. Fosse qual fosse a frase dita pela mulher, o que ficou dela nos ouvidos do vaqueiro foi este núcleo: "as aves matam o gado". Tais palavras provocam-lhe o resmungo de quem não vê nelas nenhum sentido. Essa sensação diante das palavras é, como se sabe, tão freqüente quanto problemática dentro de Fabiano. Mais uma vez surgiu para ele uma frase extravagante, uma coisa obscura, dita agora pela mulher, que deveria estar tresvariando, que provavelmente não estava regulando. Sentem-se a desconfiança e a irritação do vaqueiro diante da expressão incompreensível; no entanto, vê-se também que a frase não apenas o incomoda, mas se repete dentro dele com o fascínio de um enigma provocador, levantando a suspeita de que bem pode haver algum sentido naquela fórmula extravagante. "Um bicho de penas matar o gado"!

Fabiano entra em casa, prepara um cigarro e na tragada longa medita, olhando para todos os lados, coçando o queixo. Parece querer afastar de si o incômodo das palavras sem sentido; mas ainda quando afirma para si mesmo: 


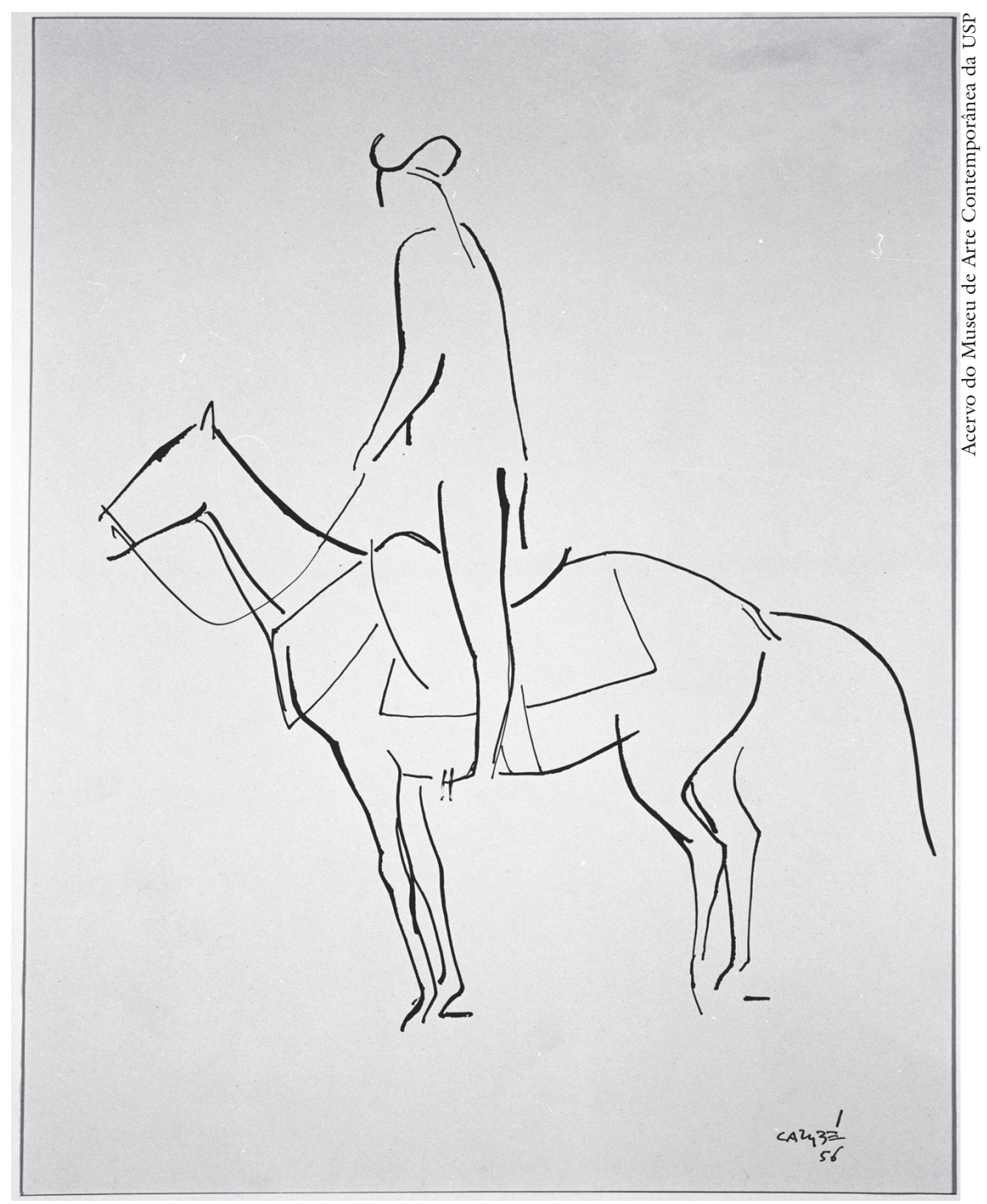

Homem a cavalo, 1956. Nanquim s/papel. Carybé.

“-Chi! Que fim de mundo!”, o leitor talvez possa desconfiar de que esse fim de mundo não se refira apenas à paisagem observada, mas ressoe vagamente uma sensação de vazio diante da frase que se ouve e não se compreende. O fato é que as palavras não the saem da cabeça. Diz o narrador que "A frase dela tornou ao espírito de Fabiano e logo a significação apareceu". Não se pode desmerecer a conjugação da palavra espírito ao fato de que a significação apareceu. Dentro do rústico Fabiano, no centro mais íntimo de suas reflexões ocorre de súbito a iluminação de um significado. Já não são palavras simplesmente ouvidas e estranhadas, as da mulher: são palavras acolhidas e compreendidas numa atividade interior. O narrador acompanha, amorosamente e passo a passo, essa elaboração da consciência, que encontra a lógica da seguinte sucessão: as arribações bebem 
a água e a esgotam; o gado morre de sede; logo, as arribações matam o gado. Não apenas acompanha como sublinha a divisão desses passos, pontuando-os e separando-os (tão ao gosto do estilo de Graciliano) com os "Bem [...] Muito bem [...] Estava certo", que dão conta da satisfação progressiva de quem afinal articula plenamente o sentido do que aparecera como um absurdo. Matutar pode ser muito proveitoso: Fabiano "esqueceu a infelicidade próxima, riu-se encantado com a esperteza de sinhá Vitória”.

Esse instante de felicidade em meio aos infortúnios abre uma brecha extraordinária para Fabiano e para o alargamento da novela. É preciso repisar a passagem, em seus ditos e subentendidos, para avaliar sua importância.

Do ponto de vista do leitor, a frase de sinhá Vitória é uma fórmula quase banal, associando uma causa a um efeito sem a preocupação de explicitar o nexo entre ambos; meninos de escola podem não apenas reconhecer o sentido de contexto da frase "As aves matam o gado" como localizar aí uma figura de linguagem. Com a esperteza de sinhá Vitória, tão respeitada por Fabiano ("Uma pessoa como aquela valia ouro"), o vaqueiro sem rumo e sem escola vê a possibilidade de aprender, e de fato aprende, e se rejubila. Diriam alguns que o retirante, menos capaz que a mulher de promover rápidas e justas associações, apenas acabou encontrando a lógica simples de uma expressão a princípio obscura para ele; mas quero crer que ele encontrou muito mais que isso. Afora a lógica, que leva à significação, Fabiano encontrou nas palavras expressivas a presença viva da poesia. Vale dizer: a partir do reconhecimento dos nexos implicados na figura de linguagem, deu-se conta de um mecanismo de pensamento ao mesmo tempo verdadeiro e belo, da possibilidade de o poético agitar-se dentro de si mesmo.

Veja-se mais de perto o arremate dessa passagem: “Aquela hora o mulungu do bebedouro, sem folhas e sem flores, uma garrancharia pelada, enfeitava-se de penas". A frase é extraordinária, com esse acúmulo de insinuações e sugestões. Trata-se de um instante preciso (aquela hora), do instante em que Fabiano, tocado e iluminado intimamente pelo poder da revelação, parece prolongar o sortilégio da figura compreendida: não compartilham ele e o narrador a transfiguração de um novo olhar sobre a paisagem? As arribações são agora as folhas e as flores que faltam ao mulungu ressecado, e a árvore enfeita-se de penas. Novas figuras se produzem (agora são metáforas), prolongando aquele instante em que Fabiano riu-se encantado.

Sim, trata-se apenas de um momento. Ao prosseguir a narração, a que não falta um rigoroso paradigma realista, o narrador faz ver que Fabiano deseja ver aquilo (o mulungu com as aves) de perto, e o encanto se desfaz, e o vaqueiro atira nas aves malditas, espantando e matando algumas arribações, e vê os galhos queimados surgirem de novo nus, antes de se recobrirem outra vez com as penas das agourentas, que parecem cobrir o mundo todo. Ainda assim, esses malditos bichos parecem continuar a provocar em Fabiano associações e figuras: "Se não fossem eles, a seca não existiria”. 
Esse instante de compreensão e de magia que destaquei na passagem analisada gera, em minha leitura, alguma conseqüência para a interpretação geral da personagem Fabiano e da própria novela. $\mathrm{O}$ vaqueiro vive, naquele preciso momento, a abertura, ainda que fugaz suspeição, de um novo caminho para o mundo e para dentro de si mesmo. Trata-se da capacidade de estabelecer relações até então insuspeitadas entre as coisas, de ver nas palavras e nas figuras a possibilidade de sínteses iluminadoras, de encontrar na expressão das palavras e da poesia não uma antinomia para o real e o concreto, mas um modo ao mesmo tempo belo e justo de percebê-lo, em que há a gratificação momentânea do espirito.

É bom lembrar que, ainda menino, Graciliano experimentou, num momento especial de sua vida, a força tremenda dessa gratificação: leia-se, em Infância, o capítulo "Os astrônomos". Nele, o menino de nove anos, ainda meio analfabeto, sente os obstáculos da prosa confusa dos textos que lhe dão a ler, e se qualifica a si mesmo como bruto em demasia. No entanto, a prima Emília, com doçura e paciência, provoca-o: se os astrônomos conseguem ler no céu, enxergando e compreendendo as estrelas distantes, por que não havia o menino de ler a página aberta diante de seus olhos? "Não distinguia as letras? Não sabia reunilas e formar palavras?" O resto da história desse menino é bem conhecido.

O narrador faz conhecer, com Fabiano, uma situação-limite da brutalidade e do primitivismo, em que o ser está abandonado e indefeso diante de todas as forças adversas, quando se confundem as hostilidades da natureza e as dos homens poderosos, a política e as heranças da condição miserável. Mas o narrador não o deixa em paz: persegue-o em sua intimidade, a novela toda, acompanha todos os seus pensamentos, expressa-os, adivinha-os, determina-os. Por isso me parece tão expressivo aquele momento que criou para Fabiano reunir e formar palavras, para Fabiano mostrar-se capaz de ler o mundo, potencializando a mesma luzinha que surgira para o menino Graciliano (de novo em Infância), quando começou a suspeitar de que seria capaz de ler.

Não sei se acerto em ficar, como fico, com essa imagem de Fabiano, tão pontualmente extraída de Vidas secas. As questões abarcadas pela novela são muitas, e complexas. Talvez esteja apostando em demasia nos provimentos de uma educação verdadeira, na força não apenas sensível, mas cognitiva da poesia. O fato é que aquela passagem com Fabiano, sinhá Vitória, o mulungu, as arribações e as palavras que instigam e se revelam ganhou nas mãos do nosso escrupuloso e rigoroso autor uma tal vivacidade e uma tal entonação que é impossível esquecê-la.

(dezembro / 2003) 
Notas

1 Para as citações, tomarei a $91^{a}$ edição (Ramos, 2003).

2 Este texto origina-se de uma palestra sobre Fabiano, no curso "Perspectivas do Século XXI - Personagens da Literatura Brasileira”, promovido pelo Espaço Cultural CPFL - Campinas e coordenado pelo Prof. Alcir Pécora.

3 Esta questão-chave foi interpretada por Alfredo Bosi (1988) em “Céu, inferno”.

Referências bibliográficas

BOSI, A. Céu, inferno. São Paulo: Ática, 1988.

CARPEAUX, O. M. Visão de Graciliano Ramos. In: __. Origens e fins. Rio de Janeiro: CEB, 1943.

LINS, A. Valores e misérias das vidas secas. Prefácio. In: RAMOS, G. Vidas secas. 27.ed. São Paulo: Martins, 1970.

NETO, João Cabral de Melo. Graciliano Ramos. In: Poesia completa (1940-1980). Lisboa: Imprensa Nacional, Casa da Moeda, 1986.

RAMOS, G. Infância. 8.ed. São Paulo: Martins, 1970. . Vidas secas. 91.ed. Rio de Janeiro: Record, 2003.

RESUMO - Busca-se, neste ensaio, focalizar vários aspectos e implicações da composição do personagem Fabiano, no romance Vidas secas, de Graciliano Ramos, relevandose, sobretudo, a possibilidade, aberta pelo narrador, de surpreender no protagonista o grande prazer que lhe advém da compreensão das palavras e, com elas, da realidade a que se referem.

PALAVRAS-CHAVE: Graciliano Ramos, Vidas secas, Fabiano, Linguagem e realidade, Composição de personagem.

ABSTRACT - This essay focuses on several aspects and implications of the composition of the character Fabiano in Graciliano Ramos' novel Vidas secas, in order to emphasize the possibility - opened by the narrator - of surprising the great pleasure that succeeds to the main character when he understands the words and, with them, the reality they refer to.

KEYWORDS: Graciliano Ramos, Vidas secas, Fabiano, Language and reality, Character's composition.

Alcides Villaça é professor titular de Literatura Brasileira da Faculdade de Filosofia, Letras e Ciências Humanas da USP. @- acvillaca@uol.com.br

Recebido em 7.2.2007 e aceito em 21.2.2007. 